\title{
Research in translation and knowledge mediation in medical and healthcare settings ${ }^{1}$
}

\section{Vicent Montalt-Resurrecció}

Universitat Jaume I

Mark Shuttleworth

Imperial College London

\section{Background}

"A word, discourse, language or culture undergoes 'dialogization' when it becomes relativized, deprivileged, aware of competing definitions for the same thing. Undialogized language is authoritative and absolute."

(Bakhtin, 1935/1981, p. 427)

Health-defined by the World Health Organization as "a state of complete physical, mental and social well-being and not merely the absence of disease or infirmity" (Preamble to the Constitution of the World Health Organization) - is one of the most fundamental values in today's societies. The physical, mental and social aspects of health indicated by the WHO suggest contexts in which communication is bound to be a major contributing factor.

\subsection{Medical and healthcare settings}

Medical and healthcare settings are embedded in a complex and varied continuum of communication, interaction and dialogue-ranging from the laboratory to the clinic and to patient education - in which participants of all kinds-patients, physicians, nurses, the general public, researchers, healthcare managers, policy makers, technicians, journalists, writers, translators, interpreters, etc. - each with different linguistic and cultural backgrounds, take part in different ways and for different purposes. In such a continuum of communication, interaction and dialogue, many genres and forms of discourse co-exist. Because of the complexity and variety of these different forms of interaction, medical and healthcare settings offer a rich environment for research in translation and interpreting from a "dialogic" (Linell, 2009) perspective.

Medical and healthcare settings are defined in this paper by the social interaction and discursive processes that take place in them as much as by the research processes, therapeutic actions, specific concepts and knowledge repositories that constitute them. Knowledge, in the previous sentence, is taken to mean the factual information accumulated collectively 
across centuries through processes of various kinds, one of which is scientific research. However, knowledge also refers to the individual and social act of knowing, of being aware of something. And, of course, one cannot acquire the former without the latter.

\subsection{The construction of knowledge}

In his Ethics, Spinoza (1632-1677) establishes several ways of knowing. According to him the most basic form of knowing is the immediate perception achieved through our senses. The second way of knowing is through symbols, that is, "[...] from the fact that having read or heard certain words, we remember things and form certain ideas concerning them, similar to those through which we imagine things [...]" (Spinoza in Runes, 1957, p. 197). Finally, Spinoza refers to reason and intuition. In this issue of Linguistica Antverpiensia New Series - Themes in Translation Studies, we are particularly interested in knowledge acquired through symbols such as words, texts, discourses and other representations, which are all mediated ways of knowing.

In his Philosophy of Symbolic Forms, Cassirer (1874-1954) explores the symbolic nature of human cognition and communication and proceeds to underline the constructive nature of symbolic forms and actions. According to him, we do not know the world directly but through the mediating power of symbols. We can access reality only through the symbolic mediation of concepts and signs, never in an immediate way (Cassirer, 1923/1998, p. 20).

In fact, we construct knowledge by means of symbols, and in particular verbal symbols, that is, words and the concepts that they refer to. According to Cassirer, scientific knowledge in any discipline is a construction or symbolic elaboration that we human beings make out of a portion of the reality surrounding us. This construction or symbolic elaboration is always carried out under certain cognitive and socio-cultural conditions.

As pointed out by Cassirer (1923/1998, p. 14) the fundamental concepts of any science, as well as the means through which it formulates its questions and finds its solutions, are not passive copies of a pre-existing entity, but the intellectual symbols created by that particular science. Scientific concepts in general and medical concepts in particular do not exist in nature, but are constructed by human beings (see Vandaele \& Béland, in this issue). Medical language is the semiotic expression of knowledge and is also determined by cognitive and socio-cultural conditions.

For Cassirer (1923/1998, p. 27), the verbal sign is not merely the final wrapping of thought, but its essential organ. The sign does more than simply serve the communication of a given content that is already out there 
waiting to be expressed and shared. Rather, the sign is the instrument through which such content is actually defined, categorized and fully constituted (Montalt-Resurrecció, 2005, pp. 59-60).

Friedman (2011) points out that what is central in Cassirer's philosophy is in line with the following statement:

The conception of human beings as most fundamentally "symbolic animals" interposing systems of signs or systems of expression between themselves and the world, then becomes the guiding philosophical motif for elucidating the corresponding conditions of possibility for the "fact of culture" in all of its richness and diversity. (p. 1)

Functional Systemic Linguistics has focused on the link between knowledge, language, communication and cognition. According to Halliday (1998),

[...] the grammar of every [natural language] is a theory of human experience [...] [it] is also an enactment of interpersonal relationships. These two functions, the reflective and the active, are each dependent on the other; and they, in turn, are actualised by a third function, that of creating discourse." (pp. 185-186)

Following Cassirer and Halliday, it can be argued that language does not simply reflect or codify something that is already there. There are no natural categorizations (see Pritzker, in this issue), but

[...] many ways in which the phenomena of our experience can be seen to be related to one another. What the grammar does is to impose a categorisation: it treats a certain cluster of phenomena as alike in certain respects, and hence sets this cluster apart from others which it treats as being different. (Halliday, 1998, p. 187)

In short, "[...] the way things are is the way our grammar tells us that they are" (Halliday, 1998, p. 187).

One of our starting points is that there are far-reaching links of interdependence—as yet unexplored-between knowing, communicating and mediating. The reasons why these links have not been explored so far are complex and varied. Latour and Woolgar (1986) have responded to this lack of awareness of the symbolic and rhetorical nature of scientific knowledge, and from their ethnographic research in the science laboratory they come to the conclusion that "[scientific] writing is not so much a method of transferring information as a material operation of creating order" (p. 245). 
In other words, when writing, scientists are not merely transcribing what is already clear in their minds. Text-making goes beyond materializing or expressing something that already exists in the mind and goes hand in hand with sense-making. By communicating verbally and nonverbally, we constantly shape and reshape-and often create, as in the case of neology - the scientific concepts that we need for our purposes as well as the arguments in which they are embedded and the social interactions that we pursue.

The authors of primary knowledge can be viewed as the first translators whose task it is to conceptualize and reconceptualize newly discovered entities and attributes of already defined entities (see Vandaele \& Bélard, in this volume).

Bazerman (1998) goes one step further and states that the abovementioned interdependence between knowledge and communication has actually been surpressed. He also points out some of the reasons why:

Over the past centuries, several forces have tended to surpress our consciousness of the rhetorical, communicative and symbolic character of scientific knowledge-thereby suppressing the awareness of the role of language in the production of knowledge: the desire to get closer to the material object and the empirical experience of it; the warranting of the representation through material practice; and the desire to remove misleading forms of representation. (p. 15)

One of the consequences of this suppression is a radical separation between knowledge, on the one hand, and language and communication, on the other. Even communication among experts is often seen as a secondary process, epistemologically much less relevant than knowledge "itself".

\subsection{Knowledge and translation}

The subsidiary, inferior nature ascribed to communication is seen even more clearly outside highly specialized scientific circles. As highlighted by Fuller (1998, p. 35), popularizing practices have often been rejected as "simplifications" and "adulterations" of scientific truth by the scientific community, as if science-and medicine in our case-could not be intrinsically accessible to the lay person.

Therefore, mediating intraculturally and interculturally and intralingually and interlingually are viewed as an unavoidable inconvenience that distorts "pure" knowledge. Such ideas are ideologically loaded in that they establish hierarchies that separate experts from lay people. Highly specialized registers and discourses are seen to occupy a 
privileged position in which experts hold power, whereas non-experts have little say in what can be described as a highly monological environment.

Such a belief in "pure" knowledge and the supression of our consciousness of the rhetorical, communicative and symbolic nature of medical and healthcare knowledge affects or can affect the way in which translation in medical and healthcare settings is studied (or not) and understood. In the context of translation studies, the old conduit metaphor can be taken to mean that there is a source text and a target text, and that the operation activated between them consists of merely transmitting the information from source to target in the most accurate way (Reddy, 1979). In line with the views on the linguistic construction of knowledge discussed in Section 1.2, many of the contributions to this issue demonstrate that such metaphors are no longer adequate for the description of the intricacies and complexities that constitute translations engaged in knowledge mediation. What is more, the monological, static view of communication in medical and healthcare settings, in which researchers and health professionals occupy the central position, and in which they are the only ones to generate true knowledge, is becoming obsolete. A more dialogical view is emerging, which reflects the complexity and variety of forms and processes at work in different communicative settings. In this emerging dialogical view, the patient is beginning to occupy the centre of attention and interaction (for a review of the concept of patient-centredness in today's healthcare, see Krystallidou, in this volume).

\subsection{Knowledge mediation}

The constructive power of symbols in general and verbal language in particular resides in the dialogism that inspires much of the research presented in this volume. But constructionism should not be misunderstood. As Linell (2009) writes,

[...] the term "constructionism" may invoke unfortunate associations of "fabrication", as if our understanding of the world is entirely fictive, just "stories" told by people who hold certain interests. Surely, there are myths and fantasies, individual as well as collective, that are at best indirectly related to anything "real", but this is not true of most of our everyday pratical knowledge, nor of course of scientific knowledge. When we "construct" the world, it is a question of intersubjective co-construction with the help of others and artifacts. It is also a partial construction in the sense that the world itself provides the material for construction. (p. 19) 
According to Linell, many dialogists prefer the term "mediation" precisely because the term "construction" is liable to be misinterpreted. Very much in line with Cassirer, Linell (2009) asserts that

Our understandings of the world come to us in a necessarily mediated form, never "immediately", at least not in an absolute sense of being entirely unaffected by the capacities and limitations of the cognising subject. It seems reasonable to distinguish between basically three or four (interrelated) types of mediation. Note, however, that we take "mediation" to mean co-constitutive mediation, that is the mediating means (resources, apparatuses) are not merely "neutral" vehicles for supporting the interaction (or causal relation) between some pre-existing entities, such as objects in the world and mental concepts. (pp. 19-20)

At this point, it is worth underlining the two sides of the same coin that converge in the co-construction of knowledge: mediating means and mediators. Each language and culture - in both the national-ethnic and the socio-professional senses, as we will argue in Section 1.5-has different resources and apparatuses that reflect asymmetries with other languages and cultures, and that constitute a rich object of study. A situation in which a foreign patient engages in dialogue-either orally or through written texts-with a health professional who writes or speaks in a different language constitutes a clear example of how interlingual aspects converge with both national-ethnic and socio-professional aspects of culture.

Like translators, mediators are no longer understood as neutral vehicles or passive conduits for the transmission of pre-existing entities. They are viewed as co-constructors of knowledge and meaning-making symbols, be it within the same language or in a different target language. In fact, in the field of interpreting, contributions (e.g., Angelelli, 2004; Bolden, 2000; Metzger, 1999; Roy, 2000; Wadensjö, 1992, 1998) have evolved over the past two decades towards an understanding of the role of the interpreter as an interactive participant in cross-cultural communication rather than as simply someone who relays linguistic messages from one language to another (Angelelli, 2004).

Among the types of mediation proposed by Linell (2009) perceptual, practical, artifact-based, etc.-and very much in Spinoza's way of thinking, we find semiotic mediation: "[...] the interactional and contextual construction of meaning builds on the use of signs: words and other symbols [...]" (p. 21).

From the perspective of translation studies, mediation has been defined as "[...] the extent to which translators intervene in the transfer process feeding their own knowledge and beliefs in their processing of a text" (Hatim \& Mason, 1997, p. 147). Hatim and Mason (1997) establish three types of mediation: (1) minimal mediation, which Venuti (1995) calls 
foreignization, (2) partial mediation and (3) maximal mediation, also referred to by Venuti (1995) as domestication. These categories are based on interlingual translation in intercultural contexts, in which culture is defined in national and ethnic terms.

When we shift to intralingual translation in contexts where culture is viewed in socio-professional terms, that is, where culture is constituted of different knowledge and discourse communities that do not share many of their resources and apparatuses, the definition by Hatim and Mason (1997) seems to work in that mediators-translators and interpreters-all tend to "feed their own knowledge and beliefs in their processing of a text" (p. 147). They do so in order to facilitate new audiences to join the dialogue from different epistemological perspectives, thus moving away from a monological framework, in which lay audiences eager to become involved feel very much like "foreigners" or outsiders with no right to talk. In this context, mediators, rather than culturally "domesticating" the source text, recontextualize it to make it accessible and counterbalance the experts' monologue. Hence, accessibility, dialogue and participation become critical elements in mediation processes and ends.

\subsection{Recontextualization and reformulation}

Some types of recontextualization and reformulation have received attention from translation studies scholars from different perspectives. For example, from a system-oriented perspective Lefevere (1985) and Hermans (1999) are among the authors to have drawn attention to rewritings of different kinds, such as adaptation for children or summary. From a functional perspective, Nord (1997) has introduced the notion of heterofunctional translation to designate translations in which "[...] the function or the functions of the original cannot be preserved as a whole or in the same hierarchy for reasons of cultural and/or temporal distance" (p. 51). Heterofunctional translation is often referred to as transgeneric translation or genre shift (Montalt-Resurrecció \& González Davies, 2007) because a change of function in the target text often corresponds to a change of genre in the target culture.

To return to our healthcare settings, now that we have argued that primary knowledge in any research process is already an act of construction, an act of mediation, an act of translation (see Section 1.2), we are in a position to argue further that the construction of medical knowledge is not restricted to communication among experts. Medical knowledge is constantly recontextualized in response to the rich and complex variety of dialogues between different knowledge and discourse communities.

"Recontextualization" and "reformulation" are thus two of the most critical concepts in this issue. Martin and Veel (1998, pp. 83-85) highlight three reasons why scientific discourse recontextualizes. The first and most 
obvious reason is what they call "the emergence of new fields of scientific activity" (Martin \& Veel, 1998, p. 83). The second reason is "new sets of social relations for users of scientific discourse" (Martin \& Veel, 1998, p. 84). A third kind of recontextualization takes place "as new modes of representing and (re)producing knowledge emerge" (Martin \& Veel, 1998, p. 84). Our main concern in this issue is new sets of social relations for users of medical and healthcare knowledge. At the centre of these new sets of social relations in medical and healthcare setting, we find patients.

For our own purposes, we will differentiate recontextualization-the move to a target context with different participants, purposes, expectations, values, etc.-from reformulation-a textual operation of rearranging and reexpressing the content in a different target text. In addition, we will apply these terms to interactions both within the same language and culture, and between different languages and cultures. Both recontextualization and reformulation can be observed at different levels of discourse.

Consider, for example, "de-terminologisation" (Montalt-Resurrecció forthcoming; Montalt-Resurrecció \& González Davies, 2007;), an umbrella term that includes explanation, definition, exemplification, illustration, analogy, comparison and substitution by a more popular term, among others:

It is a process of recontextualisation and reformulation of specialised terms aiming at making the concepts they designate relevant to and understandable by a lay audience. This process is motivated by specific cognitive, social and communicative needs, and takes place as part of a broader process of recontextualisation and reformulation of discourse. (Montalt-Resurrecció, forthcoming)

Determinologization (see Ezpeleta Piorno, Muñoz-Miquel and Tercedor \& López-Rodríguez, in this issue) is the opposite of "terminologisation" understood as "[...] a process of semantic and lexico-grammatical distillation through which a given concept specializes and becomes a differenciated term [...]" (Montalt-Resurrecció, forthcoming). This process is the kind of mediating operation that field experts carry out to label the entities that they conceptualize.

Recontextualization and reformulation in medical and healthcare settings prompt us to consider culture in two different-yet often complementary-ways. On the one hand, we will take culture to mean the set of values, beliefs, institutions, preferences, habits, etc. shared by a particular national, ethnic or linguistic group. On the other hand, we need to take on board a second, narrower, view of culture as the set of values, beliefs, institutions, preferences, habits, etc. shared by well-defined knowledge communities-such as health professionals, patients, biomedical researchers-within the same national, ethnic or linguistic group. 


\subsection{Shifts in recontextualization and reformulation}

The "shift", a well-established concept in translation studies, refers fundamentally to "[...] small linguistic changes ocurring in translation of ST to TT" (Munday, 2001, p. 55). Although the term was first introduced by Catford (1965), Vinay and Darbelnet (1958) had already referred to the same concept in their translation procedures. Van Leuven-Zwart's concept of translation shifts $(1989$, 1990) comprises two models: (1) a microstructural comparative model with three main categoriesmodulation, modification and mutation and (2) a macrostructural descriptive model, designed for the analysis of translated literature (Munday, 2001, p. 65).

Shifts are at the heart of recontextualization and reformulation both intralingually and interlingually. As will be seen in the articles in this volume, shifts can take place in written, oral and visual modes, and at different levels, ranging from lexical items to bigger units such as genre (see Montalt-Resurrecció \& González Davies's (2007) concept of genre shift).

This special issue also demonstrates that shifts can affect personal reference (de Pedro Ricoy), specific notions (Major \& Napier, Vandaele \& Béland), terminological units (Pittarello, Tercedor \& López-Rodríguez), syntactic structures and genre conventions (Ezpeleta Piorno, MuñozMiquel) as well as discursive practices (Pritzker).

\subsection{Research questions}

There are a number of questions that arise from the perspective that we have presented so far. What happens to knowledge, language and communication when knowledge is socially co-constructed and circulated both in interlingual and intralingual contexts? What roles do translators and interpreters play in knowledge mediation? How do they behave? How does their behaviour affect and become affected by their audiences and contexts? How is knowledge mediated between "national", ethnic cultures? How is knowledge mediated between different professional and non-professional cultures? How do different knowledge and discourse communities establish (or not) their dialogues? How are concepts and arguments shaped and reshaped in the different genres of the complex communicative continuum of medical and healthcare settings? How do language and social interaction vary in different genres? Some of these questions and other issues have been addressed by the authors of this volume, as will be seen in Section 2 . 


\section{Individual contributions to the volume}

Although a common thread through all the articles in this issue is knowledge mediation in medical and healthcare settings, the different contributions focus on a wide variety of cultural contexts (Australia, Belgium, China, Denmark, Germany, Italy, Mexico, the Netherlands, Norway, Spain, the United Kingdom and the United States of America), of languages (Chinese, Danish, Dutch, English, German, Italian, Norwegian and Spanish) and of genres (both oral-consultation and other medical encounters-and written-patient information leaflets, summaries of product characteristics, medical leaflets, original articles and summaries for patients).

The contributions to this volume can be grouped in several ways, depending on the criterion that one applies, and all of these appear to be virtually equally coherent. One could organize the articles in terms of interlingual vs. intralingual mediation, written vs. oral mediation, mediation across time, space and knowledge communities, mediation across different language pairs, mediation across different genres, etc. However, since our main purspose is to underline the relevance of knowledge mediation as a concept and practice, we have assembled the articles into three main groups based on Halliday's three metafunctions (see also Section 1.2): (1) participant-centred knowledge mediation (Nisbeth Jensen \& Zethsen, de Pedro Ricoy, Felberg \& Skaaden, Krystallidou, Pittarello), (2) text-centred knowledge mediation (Pritzker, Ezpeleta Piorno, Muñoz-Miquel) and (3) concept-centred knowledge mediation (Major \& Napier, Vandaele \& Bélard, Tercedor \& López-Rodríguez). Of course, there are overlaps between these three general groups that deserve attention, and these will be briefly addressed in the following sections.

\subsection{Participant-centred approaches to knowledge mediation}

The first group of articles focuses on the interpersonal dimension of discourse, that is, on the roles, behaviours and performances of the different participants in the process - translators, interpreters, medical professionals, patients, patients' relatives, the general public, etc.

The Patient Information Leaflet (PIL) is a crucial genre for adequate communication between health professionals, patients and pharmaceutical laboratories as far as taking medicines safely and efficiently is concerned. Although PILs are intended to be easily understood by patients, a number of researchers have highlighted that many PILs are not user-friendly. What is more, because of difficulties in understanding some of the concepts that PILs contain, many patients do not take their medicines as prescribed. The fundamental cause of this lack of reader-friendliness may be found in the qualifications and academic backgrounds of the translators of PILs. Nisbeth 
Jensen and Zethsen address this important issue in their article entitled Translation of Patient Information Leaflets: Trained Translators and Pharmacists-cum-Translators-A Comparison. They start from the following question: do trained translators translate PILs in a different way from pharmacists-cum-translators? Their hypothesis is that subject-matter experts translate differently from trained translators in cases where expertlay communication is further complicated by interlingual translation. In their analysis, they focus their attention on two elements that affect comprehension in a negative way in this particular genre: (1) Greek and Latin terms and (2) nominalizations. One of their main findings is that pharmacists-cum-translators make use of more Greek and Latin-based terms and introduce more nominalizations than trained translators. Indeed, their findings demonstrate that these two groups of professionals really do translate PILs in different ways, and that the differences affect readerfriendliness.

Patients not only need highly specific descriptions and instructions concerning their medicines, but also more general information about the conditions affecting them. Medical leaflets (MLs) are designed to fulfil the wishes of patients to know more about their diseases in order to participate more effectively in their therapeutic process and to take informed decisions about issues concerning their health. But communicating factual information is not an easy matter and cannot be separated from interpersonal and interactional aspects. Knowing the factual information needed is the first step in the process and establishing the right kind of dialogue with patients is a further-probably more challenging - step. This is especially important in the case of specific groups, such as the mental health patients investigated by de Pedro Ricoy. In Reading Minds: A Study of Deictic Shifts in Translated Written Interaction between Mental-Health Professionals and Their Readers de Pedro Ricoy draws our attention to writer-reader interaction patterns and how they differ across cultural and linguistic settings. Her aim is to compare the interaction between mentalhealth experts and their readers before and after knowledge has been mediated through translation between English and Spanish. She focuses on how writer-reader interaction is achieved in written texts addressed to patients in the clinical context of mental health. In particular, she investigates non-obligatory shifts of personal reference and discovers that there is a shift in tenor, which reflects a change in the relationship between the participants. In particular, the explicit difference between addressees and other participants that we find in the source text tends to be blurred in the target text.

In the next article, we move from the written to the oral mode and to the complex area of medical encounters. Patient-centredness is an emerging paradigm in healthcare, in which patients are moved to the very centre of attention in communicative processes. Patient-centredness is challenging in that it represents a radical departure from doctor-centred or medicine- 
centred approaches to healthcare. In On Mediating Agents' Moves and How They Might Affect Patient-Centredness in Mediated Medical Consultations Krystallidou problematizes this key notion in heathcare systems today. She looks at patient-centredness in multilingual, multicultural settings and focuses on whether linguistic and cultural mediation affects its essence. Her data are taken from a corpus of transcribed video-recorded mediated consultations that took place in an urban hospital in Belgium. Patientcentredness is potentially compromised in interlingual and intercultural situations where an interpreter is required because the immediate contact between patients and health professional vanishes, and with it the immediacy and individuality expected in patient-centred environments. Krystallidou's study offers a potential challenge to patient-centredness as it occurs within a mediated medical encounter in which a self-professed patient-centred doctor is participating. It accomplishes this by attempting to study the different ways in which the participants in a medical encounterthe doctor, the patient and the mediating agent (MA) — can have an impact on the communication, and the overall relationship that exist between doctor and patient. Factors considered include both verbal and non-verbal cues (such as gaze). More generally, the article also seeks to make a contribution to the fields of linguistics, translation studies and medical communication.

In The (De)construction of Culture in Interpreter-Mediated Medical Discourse Felberg and Skaaden address perceived communication problems with minority patients, which are often ascribed to cultural differences. Culture is frequently used as an explanatory tool for most perceived complications. According to the authors, many of the perceived problems have nothing to do with culture, but with a lack of concentration or a lack of language proficiency — often caused by ad-hoc solutions such as using the patient's relatives, sometimes even children, to deal with situations where a professional interpreter is required. Felberg and Skaaden not only question the real causes of such perceived problems but also warn that resorting to the concept of culture may lead to "othering" minority patients. By "othering", they mean emphasizing the difference between Us and the Other, downplaying "their culture" and creating a potential to ascribe the source of the problems to attributes of the Other. One consequence of "othering" minority patients is that it makes it possible to disclaim one's own responsibility for problem solving. Another consequence is that it conceals rather than reveals the problem. Felberg and Skaaden propose several alternative strategies to overcome perceived communication problems. Their aim is to avoid malpractice in medical professionals, which may threaten not only minority patients' health but also the integrity and status of medical personnel.

The study by Pittarello, a paper entitled Medical Terminology Circulation and Interactional Organization in Interpreter-Mediated Medical Encounters, is based on an analysis of two medical encounters that 
took place between foreign tourists and medical practitioners in a hospital in northern Italy. These encounters are subjected to a qualitative analysis to determine the way in which medical terminology circulates (e.g., in terms of the medical practitioners' choice of a "professional" or a "nonprofessional" variety of medical language). Pittarello also investigates the linguistic and social organization of the mediated interaction in terms of turn-taking, sequences, communication exchanges and the shifts that occur (e.g., in register and interaction structure) as a result of the way in which interlocutors' utterances are translated. Within this context, the paper aims to examine the approaches used by medical interpreters in the two encounters analysed to translate medical terminology and to promote or to exclude the active participation of the different interlocutors. Of key importance for boosting or impeding participation is the predominance of dyadic (i.e., monolingual) or triadic (i.e., bilingual interpreter-mediated) sequences and in particular the shifts that are introduced. Medical interactions are also seen as enshrining specific expectations, which are chiefly cognitive in nature (e.g., those based on observations about what is going to happen) but can also be affective (i.e., those that involve the selfexpression of participants). The encounters offer interesting, in-depth data that present interactions as highly nuanced communicative situations (such as the use by the doctor of the TL in the presence of the interpreter) that do not always conform to previously posited assumptions about what occurs in such interactions. The paper reaches a number of concrete conclusions on the basis of the encounters studied.

The aim of the paper by Ross and Magris (The Role of Communication and Knowledge Management as Evidenced by HCP Vaccination Programs in the Netherlands, Germany and Italy: Possible Suggestions for Medical Translators) is to offer insights into the interlingual mediation of health communication in three European countries and to look at its implications for medical translation practice and translator training. The article studies HPV (Human Papilloma Virus) vaccination campaigns in the Netherlands, Germany and Italy and the communicationrelated factors that have affected the campaigns' success rates in each of these three countries. The focus is on the translator's role in communication and knowledge management. The paper contains a comparison of publicservice communication in the three countries under investigation, and also discusses the socio-political conditions of the campaigns as well as their outcomes. Translators are seen as "communication professionals" and "knowledge managers" who use their linguistic and cultural expertise to offer clear communication in complex intercultural situations. In this context, the paper also considers the extent of the possible overlap between medical translation and medical writing. The role of translators in disseminating medical information is seen in the social context in which it takes place, and the possibility is discussed that medical translators exercise more far-reaching choices than is usual in most areas of translation, in 
terms of the assertiveness with which medical translators act in the interests of all communication partners.

\subsection{Text-centred approaches to knowledge mediation}

As will be seen in this section, context, discourse, genre and intertextuality play critical roles in what we have called text-centred approaches to knowledge mediation.

Chinese medicine is becoming increasingly popular in many countries and cultures outside China. This popularity is motivated by and also motivates interesting dialogical processes in which the asymmetries of different medical systems become apparent. These asymmetries can be of different types-mainly conceptual, social and cultural-and they offer an extremely rich field for translation-oriented research. In Translating the Essence of Healing: Inscription, Interdiscursivity, and Intertextuality in U.S. Translations of Chinese Medicine Pritzker focuses on a highly functional genre, the textbook, which in her case is deeply rooted in healing practice. In line with dialogically oriented researchers, Pritzker views translation as dialogue between two parties. She considers what happens to knowledge when it is mediated between distant—geographically as well as epistemologically — medical cultures, such as Chinese Medicine-which is based on a rich textual tradition-and Western Scientific Biomedicine. In particular, she investigates what happens when Chinese medicine is translated from Chinese into English. Pritzker looks at a single Chinese term, "jing", in three different translations to demonstrate how each translation into English is an inscription of complex interrelationships in the source and the target contexts. What Pritzker calls "living translation" unveils a number of issues related to intertextuality and interdiscursivity that go beyond mere linguistic encoding, decoding and re-coding.

Following the work of some genre theorists (Bakhtin, Bazerman, Swales, Bhatia, etc.), Vilha (1999) underlines the need to look at medical genres that depend on one another as systems. In her paper An Example of Genre Shift in the Medicinal Product Information Genre, Ezpeleta Piorno looks at expert-to-lay communication, but in this case from the more comprehensive perspective of genre systems. Unlike most of the other papers, Ezpeleta Piorno's contribution is centred on the question of intralingual rather than interlingual translation. It shares with MuñozMiquel's article a discussion of determinologization and syntactic structures, and with both that paper and that of Nisbeth Jensen and Zethsen a focus on medication information designed for patients. The paper has two objectives. The first objective is to offer a description of the dynamic continuum of medical communication in the pharmaceutical sector, consisting of product information genres, that exists within the system of genres described. In this respect, the paper focuses on the restraints, the 
genre conventions and the sequence requirements that are imposed by the metagenres specific to the genre system. The second objective is to illustrate the genre shifts that occur when material is intralingually translated between the summary of product characteristics and the package leaflet. The paper presents a discussion of how various specialist-tospecialist genres (such as the summary of product characteristics and the company core data sheet) lie behind the presentation to the public of essential product-related information in the form of package leaflets (also known as PILs). The paper explores the three kinds of information that are needed by medical writers and translators: (1) conceptual, (2) contextual and (3) textual. The paper argues that translators who possess this information are able to work more efficiently on a progressive basis. Interdependence, recontextualization and reformulation play critical roles in Ezpeleta Piorno's research.

Patients increasingly wish to know more and thus be more empowered to engage in the dialogue with other participants in their healing process. Cutting-edge biomedical research may be of interest for certain groups of patients, particularly those with chronic diseases. There is a growing awareness of this need in different research settings and some biomedical journals have started to provide summaries for patients of articles originally conceived for researchers. In From the Original Article to the Summary for Patients: Reformulation Procedures in Intralingual Translation Muñoz-Miquel deals with such issues in the particular context of the research journal Annals of Internal Medicine. She draws the reader's attention to expert-to-lay translation, but in this case, intralingual translation. Recontextualization and reformulation play critical roles in this research. Greater ease of access to information and the promotion of patient education have increased the demand for medical texts aimed at a wide, non-specialized, heterogeneous audience. In this context, it is essential to know what procedures are required to make specialized knowledge accessible to non-experts. Muñoz-Miquel's paper presents a corpus-based exploratory study that describes the procedures used to reformulate, intralingually, medical knowledge from a highly specialized genre, the original article (OA), into a genre derived directly from it but addressed to laymen, namely, the summary for patients (SP). The linguistic and textual shifts that take place when translating an OA into an SP are taken as the basis for explaining the reformulation procedures used. The results of the study contribute to the characterization of the SP from a text genre perspective, and provide keys to writing and reformulating for both medical translators and experts in the field. 


\subsection{Concept-centred approaches to knowledge mediation}

Conceptual mediation focuses on what happens to factual information in communication processes and the way in which concepts are shaped and reshaped through dialogues of various kinds across space and time.

The paper by Major and Napier, Interpreting and Knowledge Mediation in the Healthcare Setting: What Do We Really Mean by 'Accuracy'?, could also have been included in Section 2.1 on participantcentred approaches to knowledge mediation because it explores the doctorpatient consultation and analyses some of the ways in which interpreters render factual information. However, we have preferred to include it in this section because it investigates interaction from the conceptual perspective of what is today perhaps a less fashionable topic within translation studies: the concept of accuracy. Major and Napier offer a nuanced discussion of this notion in the context of interpreter-mediated healthcare interaction. Their data are derived from an investigation into doctor-patient consultation role-plays conducted with professional interpreters working between Australian Sign Language (Auslan) and English. The question of how interpreters operate in this respect has not received a significant amount of attention in the existing literature. The article is the first to apply Wadensjö's (1998) taxonomy of renditions to analyse the ways in which signed language interpreters convey health information. Within this context, Major and Napier's data indicate that interpreters often produce renditions that are reduced or expanded (rather than close), but that these do not detract from the message or the interaction as a whole since interpreters respond dynamically to the situation by making implicit information more explicit, by adding cohesion, or by including visual information in the signing to make the message clearer. Although the use of role-plays can be said to represent a limitation in view of their non-authentic nature, on the positive side it can be argued that they allow researchers to carry out a systematic comparison of the performance of different interpreters. In so doing, they provide more robust data that can be used for the purposes of healthcare interpreter training.

Since scientific concepts in general and medical concepts in particular are constructed or mediated semiotically, socially and culturally - as we have pointed out in Section 1-they are not fixed entities. They not only change synchronically-across different knowledge communities, national-ethnic cultures and languages-but also diachronically. For example, we tend to think that a scientific and medical concept such as "gene" is and has always been totally objective and immutable. In fact, it has not and is not, as Vandaele and Béland show in Les Modes de Conceptualisation des Unités d'Hérédité au XIXe Siècle: Spencer, Haeckel et Elsberg. Vandaele and Béland start from the premise that the study of metaphorical conceptualizations can shed light on the understanding of both popularization and translation. Vandaele and Béland 
focus on the evolution of one crucial concept for biology and medicine, that of the unit of inheritance. According to the authors, it is important to look back at history and to study how scientific thought has evolved to achieve a better understanding of how discourse is constructed by borrowing elements from existing theories and how the metaphors that have nourished those theories have been used and translated. In very much the same way that rocks show successive geological periods, theories and their metaphorizations have left their traces in discourse up to the present. The authors formulate the hypothesis that although some well-established metaphors in biomedical discourse have become or will soon become obsolete, they are still being used either naïvely or at the service of particular rhetorical ends. In their historical analysis of this concept, the authors investigate, on the one hand, how the unit of inheritance is designated, described and conceptualized by three authors-Spencer, Haekel and Elsberg-writing at the pre-experimental period towards the end of the nineteenth century; and, on the other hand, how various metaphorical conceptualizations are expressed in English and French.

In their article entitled Access to Health in an Intercultural Setting:

The Role of Corpora and Images in Grasping Term Variation, Tercedor and López-Rodríguez provide an analysis of terminological variation. Of interest to them are, for example, the communicative reasons for choosing one term rather than another. Like Pittarello, Tercedor and LópezRodríguez are concerned with how medical concepts are lexicalized differently depending on the aspect of the concept that is being highlighted or the particular context in which the term is being used. The authors take their data firstly from an international project in the Yucatan peninsula, Mexico, that aims to provide Mayan and Spanish audiovisual materials for the promotion of healthcare, and secondly from a research project designed to investigate lexical variation. The possibilities provided by terminological variation for improving interlinguistic and intercultural communication are investigated in the paper. The study also explores ways in which corporaand, in particular, corpora of semi-specialized medical texts-can be exploited to shed light on this kind of variation by means of the use of particular lexical, grammatical and paralinguistic patterns such as search terms. Finally, the paper offers a discussion of the vital role played by images in the localization process required to bridge the gap between medical practitioners and lay audiences.

\section{Conclusions}

One thing that we hope that this publication has achieved is to show the wide variety of activities that contribute to the overall concept of what may loosely be termed "medical translation". Medical and healthcare translation is a rich area that includes multiple different modalities, activities and areas 
of expertise, and a consideration of it cannot of course be limited to purely linguistic matters such as equivalence or terminology, as would have been the case in the not-too-distant past within the discipline.

At least seven thematic tracks can be identified in this special issue: (1) expert-to-lay communication (including translation and interpreting), (2) translator and interpreter behaviour and performance, (3) the translation of specific genres, (4) intralingual translation, (5) intermodal interpreting, (6) interdiscursivity and (7) conceptual change. A number of these-or, arguably, all of them-break new ground in research terms. This multiplicity of approaches represents a wealth of perspectives, which see translation variously conceptualized as reformulation, recontextualization, dialogue and, of course, mediation. Mediation itself turns out to be a multifaceted concept that is differently reflected in each of the twelve contributions, and one that permits us to encompass such a wide range of different topics within the space of a single volume. This diversity of approaches is complemented by a similar wealth of methodologies that include the use of corpora, interviews, focus groups, and observation and analysis of both real and simulated situations.

This volume has brought together perspectives from interpreting and translation studies, and also from the study of intralingual mediation. Not explicitly discussed in these pages, but nonetheless of great importance, is the need to ensure that these separate sub-disciplines should be integrated so that a dialogue might exist between them. Interpreting can serve as an inspiration to scholars of translation in raising awareness of the non-verbal and of the truly dialogic nature of knowledge mediation, of the participants involved in the process and of how their feelings, thoughts and actions are reflected in language. Translation can inspire those who research interpreting to attend more closely to the critical importance of the verbaland in particular, of the terminological, intertextual, generic, discursive and semiotic elements that are embedded in texts. Finally, intralingual and interlingual mediation can inform each other in bringing to the fore the cultural aspects in two complementary ways. On the one hand, intralinguistic mediation, that is, adaptation for different audiences, provides those who study interlinguistic mediation with an awareness of different expert and non-expert cultures, that is, doctors, nurses, different groups of patients, general public, etc. On the other hand, scholars of intralingual translation can learn much from interlinguistic translation about the importance of awareness of different "ethnic" and "national" cultures. Although a certain amount has already been achieved, there is clearly much that remains to be done, both in terms of launching further investigations into all these individual areas and with regard to developing common repertoires of aims, priorities, approaches to and insights into this fascinating and vital area. 


\section{Acknowledgements}

We should like to thank all the contributors for their hard work and patience in complying with our constant requests for modifications during the various steps in the editing process. We are delighted with the finished product and believe that it more than compensates for the effort that has been put in by everyone. At the same time, we should like to thank the reviewers whose input was essential earlier on in the process, and to express our deep gratitude to Aline Remael for her tireless energy and unending encouragement and guidance throughout every step of the way, and also to her colleagues Katrien Lievois and Jimmy Ureel for their help in bringing the collection to the state of completion that you now see.

\section{References}

Angelelli, C. (2004). Medical interpreting and cross-cultural communication. Cambridge: Cambridge University Press.

Bakhtin, M. M. (1935/1981). The dialogic imagination: Four essays. C. Emerson \& M. Holquist (Translated into English. Russian original: four selections from Voprosy literatury i estetiki, 1935). Austin, TX: University of Texas Press.

Bazerman, C. (1998). Emerging perspectives on the many dimensions of scientific discourse. In J. R. Martin \& R. Veel (Eds.), Reading science: Critical and functional perspectives on discourses of science (pp. 15-30). London: Routledge.

Bolden, G. (2000). Toward understanding practices of medical interpreting: Interpreters' involvement in history taking. Discourse Studies, 2(4), 387-419.

Cassirer, E. (1923/1998). Filosofía de las formas simbólicas : El lenguaje. A. Morones (Translated into Spanish. German original Philosophie der symbolischen Formen. Erster Teil, Die Sprache, 1923). México D. F.: Fondo de Cultura Económica.

Catford, J. C. (1965). A linguistic theory of translation. Oxford: Oxford University Press.

Friedman, M. (2011). Ernst Cassirer. In E. N. Zalta (Ed.), The Stanford encyclopedia of philosophy (Spring 2011 Edition). Retrieved from http://plato.stanford.edu/ archives/spr2011/entries/cassirer/

Fuller, G. (1998). Cultivating science: Negotiating discourse in the popular texts of Stephen Jay Gould. In J. R. Martin \& R. Veel (Eds.), Reading science: Critical and functional perspectives on discourses of science (pp. 35-62). London: Routledge.

Halliday, M. A. K. (1998). Things and relations: Regrammaticising experience as technical knowledge. In J. R. Martin \& R. Veel (Eds.), Reading science: Critical and functional perspectives on discourses of science (pp. 185-236). London: Routledge.

Hatim, B., \& Mason, I. (1997). The translator as communicator. London: Routledge. 
Hermans, T. (1999). Translation in systems: Descriptive and system-oriented approaches explained. Manchester: St. Jerome.

Latour, B., \& Woolgar, S. (1986). Laboratory life: The construction of scientific facts. Princeton, NJ: Princeton University Press.

Lefevere, A. (1985). Why waste our time on rewrites?: The trouble with interpretation and the role of rewriting in an alternative paradigm. In T. Hermans (Ed.), The manipulation of literature: Studies in literary translation (pp. 215-243). Beckenham: Croom Helm.

Linell, P. (2009). Rethinking language, mind, and world dialogically: Interactional and contextual theories of human sense-making. Charlotte, NC: IAP.

Martin, J. R., \& Veel, R. (Eds.) (1998). Reading science: Critical and functional perspectives on discourses of science, London: Routledge.

Metzger, M. (1999). Sign language interpreting: Deconstructing the myth of neutrality. Washington, DC: Gallaudet University Press.

Montalt-Resurrecció, V. (2005). Manual de traducció cientificotècnica. Vic: Eumo.

Montalt-Resurrecció, V. (forthcoming). La desterminologització del discurs especialitzat: Una necessitat per facilitar als pacients l'accés al coneixement. Termcat: Barcelona.

Montalt-Resurrecció, V., \& González Davies, M. (2007). Medical translation step by step: Learning by drafting. Manchester: St. Jerome.

Munday, J. (2001). Introducing translation studies: Theories and applications. London: Routledge.

Nord, C. (1997). Translating as a purposeful activity: Functionalist approaches explained. Manchester: St. Jerome.

Preamble to the Constitution of the World Health Organization as adopted by the International Health Conference, New York, 19-22 June, 1946; signed on 22 July 1946 by the representatives of 61 States (Official Records of the World Health Organization, no. 2, p. 100) and entered into force on 7 April 1948.

Reddy, M. J. (1979). The conduit metaphor: A case of frame conflict in our language about language. In A. Ortony (Ed.), Metaphor and thought (pp. 284-310). Cambridge: Cambridge University Press.

Roy, C. B. (2000). Interpreting as a discourse process. Oxford: Oxford University Press.

Runes, D. D. (Ed.). (1957). The Ethics of Spinoza. New York: Kensington.

van Leuven-Zwart, K. M. (1989). Translation and original: Similarities and dissimilarities (I). Target, 1(2), 151-181.

van Leuven-Zwart, K. M. (1990). Translation and original: Similarities and dissimilarities (II). Target, 2(1), 69-95.

Venuti, L. (1995). The translator's invisibility: A history of translation. London: Routledge.

Vilha, M. (1999). Medical writing: Modality in focus. Amsterdam: Rodopi.

Vinay, J. P., \& Darbelnet, J. (1958). Stylistique comparée du français et de l'anglais. Paris: Didier-Harrap. 
Wadensjö, C. (1992). Interpreting as interaction: On dialogue interpreting in immigration hearings and medical encounters (Dissertation). Linköping University: Linköping Studies in Arts and Science No. 83.

Wadensjö, C. (1998). Interpreting as interaction. London: Addison Wesley Longman.

1 This special issue of Linguistica Antverpiensia and this article are part of the research project 2010-2012 (FFI2009-08531/FILO), funded by the Spanish Ministry of Science and Innovation (MICINN). 